\title{
The Major Acid-soluble Proteins of Bacillus subtilis Spores: Partial Amino Acid Sequence and Forespore Location of Their mRNAs
}

\author{
By HANS BLOM,${ }^{1}+$ ROBERT MORSE, ${ }^{1} \ddagger$ J. MANDELKORN,${ }^{1}$ \\ M. ARNAUD,${ }^{2} \S R$. WARBURG ${ }^{2}$ AND DONALD J. TIPPER ${ }^{1 *}$ \\ ${ }^{1}$ Department of Molecular Genetics and Microbiology, University of Massachusetts Medical \\ Center, Worcester, MA 01605, USA \\ ${ }^{2}$ Rosenstiel Center, Brandeis University, Waltham, MA 02254, USA
}

(Received 9 March 1987)

In Bacillus subtilis the $\alpha, \beta, \gamma$ and $\delta$ components comprise $80-90 \%$ of the total acid-soluble spore proteins (ASSPs). Sequence analysis demonstrates that $\alpha$ and $\beta$ share 32 of their first 36 amino acids and are closely related to the A and C ASSPs of Bacillus megaterium spores, confirming the results of analysis of their cloned genes. Despite the difference in apparent size of $\gamma$ and $\delta$, they have identical $\mathrm{N}$-terminal sequences (37 residues). Unless $\gamma$ and $\delta$ derive from very recently duplicated genes, it appears that $\gamma$ is derived from $\delta$, either in vivo or during isolation. Although the sequenced regions of $\gamma$ and $\delta$ have no homology to $\alpha$ and $\beta$, outside of the previously recognized pentapeptide recognition sequence for the spore endopeptidase, they share 10 and 15 residue peptides flanking this sequence with ASSP B of B. megaterium, but in reverse order. At least two groups of ASSPs have, therefore, been conserved between $B$. subtilis and $B$. megaterium: the multigene $A C \alpha \beta$ family and the $B \gamma(\delta)$ group. Sequence conservation in each group implies selection for functions in addition to storage. Both the $\alpha$ and $\beta$ components of $B$. subtilis ASSPs and their mRNAs are located in the forespore compartment of cells at $t_{5.5}$ of sporulation, the time of most rapid ASSP synthesis. The sizes of these transcripts (250-350 bp) and their ability to direct the in vitro synthesis of ASSPs of mature size, indicate that genes for these ASSPs are monocistronic, consistent with dispersed map location. Synthesis of ASSPs is, therefore, coordinately controlled by selective transcription in the forespore.

\section{INTRODUCTION}

Approximately $20 \%$ of the protein of dormant spores of Bacillus megaterium and $8 \%$ of that in spores of Bacillus subtilis is rapidly degraded during spore germination, providing amino acids essential for both metabolism and protein synthesis during outgrowth (Setlow, 1981; Johnson \& Tipper, 1981). These proteins comprise a group of small, acid-soluble spore proteins (ASSPs), defined by solubility in acid following dry breakage (Setlow, 1975) or spontaneous rupture of mature spores in $2 \mathrm{M}-\mathrm{HCl}$ (Johnson \& Tipper, 1981). They are synthesized coordinately, late in sporulation (Dignam \& Setlow, 1980; Tipper et al., 1981; Johnson et al., 1985) under transcriptional control by early spo genes (Johnson et al., 1985) and accumulate in the forespore (Setlow, 1981; this paper).

Three ASSPs, A, B and C in B. megaterium (Setlow, 1981), and $\alpha, \beta$, and $\gamma$ in B. subtilis (Johnson \& Tipper, 1981), make up at least $80 \%$ of the total ASSPs in both species. These are the most easily extracted ASSPs, for example, in $0.5 \mathrm{M}$-acetic acid, although a number of less wellcharacterized minor ASSPs are found when stronger acids are used for extraction (Setlow, 1981;

† Present address: Norwegian Food Research Institute, PO Box 50, N-1432 AAS-NLH, Norway.

‡ Present address: Department of Microbiology, University of Leicester, Leicester LE1 7RH, UK.

$\S$ Present address: Institut Pasteur, Rue du Dr Roux, 75724 Paris, France.

Abbreviations: ASSP, acid-soluble spore protein; DFP, diisopropyl fluorophosphate. 
Johnson \& Tipper, 1981). Among the predominant ASSPs, the two smallest (A and C, $\alpha$ and $\beta$ : each 60-70 amino acid residues in length) are closely related in biochemical properties and also show inter-species similarity, as indicated by low but distinct immunological cross-reactivity (Johnson \& Tipper, 1981; Yuan et al., 1981). In contrast, B and $\gamma$ are considerably larger and are much less closely related to the other ASSPs. $\delta$, the major new species extracted from $B$. subtilis spores by $2 \mathrm{M}-\mathrm{HCl}$, has an apparent size of about 105 amino acid residues, and otherwise resembles $\gamma$ (about 90 residues) in biochemical properties (absence of methionine, pI, behaviour on ion-exchange chromatography; Johnson \& Tipper, 1981; Johnson et al., 1985).

Degradation of ASSPs is initiated by a unique endopeptidase (Setlow et al., 1980), also produced during sporulation and stored in the spore, which is specific for glutamate-bounded pentapeptide sequences resembling Glu-Ile/Phe-Ala-Ser-Glu. This sequence occurs once in A and $C$ and twice in B and $\gamma$ (Yuan et al., 1981) and, with minor variations, in all ASSP sequences so far identified.

Cloning of genes for C (Curiel-Quesada et al., 1983) and related B. megaterium ASSPs (Fliss et al., 1986) has identified at least seven genes, belonging to a closely related multigene family. All are expressed together, although only $A$ and $C$ produce easily detectable quantities of product. Cloning of related $B$. subtilis genes, initially using the $B$. megaterium $C$ gene as probe, has recently shown that a similar family exists in $B$. subtilis (Connors et al., 1986a): four closely related ASSP genes were found, including two, $s s p A$ and $s s p B$, deletions in which result in absence of ASSPs $\alpha$ and $\beta$, respectively, from spores (Connors et al., 1986a).

We have purified $\alpha, \beta, \gamma$ and $\delta$, and obtained $N$-terminal sequences for their first 37-38 amino acid residues in order to compare these sequences with each other and with the related $B$. megaterium proteins. The sequences for $\alpha$ and $\beta$ show complete agreement with the sequences predicted for the $\operatorname{ssp} A$ and $\operatorname{ssp} B$ gene products. The $\gamma$ and $\delta$ sequences were analysed both for similarity to $B$ and to determine whether they may represent members of a second multigene family.

mRNAs for the B. megaterium A and C proteins (Dignam \& Setlow, 1980) and for the $B$. subtilis $\alpha$ and $\beta$ proteins (Tipper et al., 1981; Leventhal et al., 1981; Leventhal \& Chambliss, 1982; Johnson et al., 1985), identified by in vitro translation, are easily recovered from cells in late stages of sporulation. Both ASSPs and their mRNAs accumulate between $t_{4 \cdot 5}$ and $t_{6}$ in $B$. subtilis (from 4.5 to $6 \mathrm{~h}$ after the start of sporulation (Johnson et al., 1985). We have now characterized the mRNAs for $\alpha$ and $\beta$ by size fractionation and show that both $\alpha$ and $\beta$ ASSPs and their mRNAs accumulate in the forespores of sporulating cells. Thus the ASSP genes are expressed in the forespore, the site of accumulation of their products.

\section{METHODS}

Bacterial strains. B. subtilis strains 168 trpC2 (originally obtained from Dr H. O. Halvorson) and SMY (obtained from Dr R. Losick) were grown and sporulated in MSM medium at $37^{\circ} \mathrm{C}$ as previously described (Johnson \& Tipper, 1981). The start of sporulation, $t_{0}$, is assumed to be the point at which the exponential increase of culture turbidity abruptly changes to a slower linear rate of increase (Johnson \& Tipper, 1981). Under these conditions, spore septum formation occurs $2.5 \mathrm{~h}$ later (at $t_{2 \cdot 5}$ ), and forespore engulfment is complete at $t_{3 \cdot 5}$. Accumulation of ASSPs and of phase-white, UV-resistant and heat-resistant spores reaches $50 \%$ at $t_{6}, t_{6}, t_{7}$ and $t_{7.5}$, respectively (Johnson et al., 1985).

Gel electrophoresis. ASSPs were fractionated according to size by SDS-PAGE using gradients from 7.5 to $15 \%$ $(w / v)$ acrylamide, and according to charge by PAGE in 6 M-urea in pH $4.7 \beta$-alanine buffer, or in aluminium lactate buffer at pH 3.6 (Lauriere \& Mosse, 1982) as previously described (Johnson et al., 1985).

Forespore isolation and preparation of mother cell extracts. Cultures of sporulating cells $(100 \mathrm{ml})$ at $t_{5}$ to $t_{6}$ were harvested by pouring over crushed ice $\left(100 \mathrm{ml}\right.$ ) containing sufficient $\mathrm{MgCl}_{2}$ and $\mathrm{NaN}_{3}$ to give final concentrations of 10 and $20 \mathrm{mM}$, respectively. Cells were centrifuged $(5 \mathrm{~min}$ at $9000 \mathrm{~g}$ ), the pellets washed in $50 \mathrm{~mm}$-potassium phosphate, $10 \mathrm{~mm}$ - $\mathrm{MgSO}_{4}, 0.6 \mathrm{M}$-sucrose, $\mathrm{pH} 7.4$ (buffer S), and suspended in $10 \mathrm{ml}$ buffer $\mathrm{S}$ containing $1 \mathrm{mg}$ lysozyme $\mathrm{ml}^{-1}$. After $15 \mathrm{~min}$ at $37^{\circ} \mathrm{C}$, cells were washed twice in buffer $\mathrm{S}$ at $0^{\circ} \mathrm{C}$ by centrifugation. Lysozymetreated cells in $2 \mathrm{ml}$ buffer $\mathrm{S}$ at $0^{\circ} \mathrm{C}$ were sonically disrupted, release of phase-grey forespores being followed by phase microscopy. After 5-10 treatments (10 s each) the pellet from centrifugation $(4 \mathrm{~min}, 8000 \mathrm{~g})$ was resuspended in buffer $\mathrm{S}$, disrupted for a further two periods of $10 \mathrm{~s}$, and forespores were isolated by centrifugation $(4 \mathrm{~min}, 8000 \mathrm{~g}$ ), almost free of unbroken cells and mother cell debris. Recovery, determined by cell number (phase microscopy), was about $25 \%$ at $t_{5}, 40-50 \%$ at $t_{5 \cdot 5}$, and $50-60 \%$ at $t_{6}$. 
Mother cell extracts for ASSP isolation were prepared from the same lysozyme-treated sporulating cells as used for forespore isolation. Cells from $50 \mathrm{ml}$ cultures were suspended in buffer $\mathrm{S}(1 \mathrm{ml})$ containing $5 \mathrm{mM}$-EDTA, $2.5 \mathrm{mM}$-phenylmethylsulphonyl fluoride (PMSF) and $0.1 \mathrm{mM}$-diisopropyl fluorophosphate (DFP) and sonically disrupted, as described above (two to five $10 \mathrm{~s}$ periods). This treatment is sufficient to disrupt about half of the lysozyme-treated mother cells, leaving at least $90 \%$ of the forespores intact. After centrifugation at $4{ }^{\circ} \mathrm{C}(20 \mathrm{~min}$, $10000 \mathrm{~g}$ ), the supernatant was diluted in $50 \mathrm{~mm}$-potassium phosphate, $150 \mathrm{~mm}-\mathrm{NaCl}, 2 \mathrm{~mm}-\mathrm{EDTA}, 0.5 \mathrm{~mm}$ PMSF, pH 7.4, containing $2 \mathrm{mg}$ bovine serum albumin $\mathrm{ml}^{-1}$ (buffer I) plus $0.1 \mathrm{mM}$-DFP for immunoprecipitation (see below).

Isolation of ASSPs. For isolation of $\alpha, \beta$ and $\gamma$, dry-broken spores were extracted with $0.52 \mathrm{M}$-acetic acid at $0{ }^{\circ} \mathrm{C}$, as previously described (Johnson \& Tipper, 1981). This extraction procedure gives optimal yields of $\alpha, \beta$ and $\gamma$, and only small quantities of more basic ASSPs. ASSPs were separated from low-molecular-mass spore metabolites, including calcium dipicolinate, unidentified oligopeptides and soluble glycan fragments, by fractionation on Sephadex G10 in $0.52 \mathrm{M}$-acetic acid. Isolation of ASSPs from sonically-isolated forespores followed essentially the same procedure. Forespores were washed in $100 \mathrm{mM}$-potassium phosphate, 5 mM-EDTA, 2.5 mM-PMSF (pH 7.4; buffer A). After centrifugation, the pellets were lyophilized, dry-broken and extracted as above.

For immunoprecipitation, the lyophilized ASSP extracts were dissolved in buffer $I$ and precipitated with anti$\alpha \beta$ IgG (the IgG fraction of rabbit polyclonal antiserum raised to a mixture of $\alpha$ and $\beta$ ), as previously described (Johnson et al., 1985). This antibody precipitates both $\alpha$ and $\beta$ with high efficiency. All steps were performed at 0 $4^{\circ} \mathrm{C}$. Mother cell extracts, prepared in buffer S plus DFP as described above, were immunoprecipitated after dilution in buffer $I$ in the same manner. Immunoprecipitates were assayed by SDS-PAGE and autoradiography.

For sequence analysis, ASSP preparations were fractionated on a Waters model 660 (HPLC) system using a Waters MicrobondaPak $\mathrm{C}_{18}$ radial compression column and a $30 \mathrm{ml}$ linear gradient from 15 to $60 \%(\mathrm{v} / \mathrm{v})$ acetonitrile in $0.04 \%$ trifluoroacetic acid at $1 \mathrm{ml} \mathrm{min}^{-1}$. Protein peaks were detected by absorbance at $210 \mathrm{~nm} . \gamma$ eluted as a pure species at $27 \%$ acetonitrile and $\alpha$ plus $\beta$ as an unresolved mixture at $37 \%$ acetonitrile.

The mixture of $\alpha$ and $\beta$ was fractionated by preparative slab gel electrophoresis at $\mathrm{pH} 3 \cdot 6$. The protein bands were detected on strips excised from the gel by staining with Coomassie brilliant blue R-250, and the appropriate unstained gel regions eluted for $6 \mathrm{~h}$ at $20^{\circ} \mathrm{C}$ in $0.52 \mathrm{M}$ acetic acid/acetonitrile $(1: 1, \mathrm{v} / \mathrm{v})$. Recovery after repeated elution was $50-60 \%$. Following lyophilization, $\alpha$ and $\beta$ were individually repurified by HPLC as described above.

For isolation of $\delta$, intact spores were ruptured by stirring at $20^{\circ} \mathrm{C}$ in $2 \mathrm{M}-\mathrm{HCl}$ (Johnson \& Tipper, 1981). Extracts were chilled to $0{ }^{\circ} \mathrm{C}$, and after addition of acetic acid to $0.52 \mathrm{M}$, the $\mathrm{HCl}$ was neutralized by slow addition of $6 \mathrm{M}$ $\mathrm{NaOH}$ with rapid stirring. After brief dialysis $(4 \times 2 \mathrm{~h})$ in low-porosity dialysis tubing against $0.52 \mathrm{M}$-acetic acid and lyophilization, ASSPs were desalted on a Sephadex G10 column. Fractionation at $4{ }^{\circ} \mathrm{C}$ on carboxymethylcellulose in a linear gradient of $\mathrm{NaCl}(0-0.35 \mathrm{M})$ in $50 \mathrm{~mm}$ Tris/maleate buffer $\mathrm{pH} 6.0$ (Johnson \& Tipper, 1981) produced a mixture of $\gamma$ and $\delta$ essentially free of other ASSPs. They were fractionated from each other on a phosphocellulose column using a linear $\mathrm{NaCl}$ gradient from 0.3 to $1.2 \mathrm{M}$ in the same buffer and residual impurities were removed by fractionation by HPLC, as described for $\alpha$ and $\beta$. Both proteins eluted at $27 \%$ acetonitrile.

Sequence analysis. Purified proteins were sequenced using a Beckman model $890 \mathrm{C}$ liquid-phase sequenator using the $0.1 \mathrm{M}$-Quadrol program 102474. The phenyithiohydantoin amino acid derivatives were identified and quantified by HPLC on $\mathrm{C}_{18}$ columns, using both acetonitrile and methanol elution gradients. Serine was identified qualitatively as dehydroserine. Since $\alpha, \beta$ and $\gamma$ are devoid of cysteine (Johnson \& Tipper, 1981), and neither $\gamma$ nor $\delta$ labels with $\left[{ }^{35} S\right]$ sulphate (unpublished observations), this identification is unique.

Isolation of RNA. Total RNA was extracted from sporulating cells by suspension of washed pellets from 1-litre cultures in $m$-cresol $(5 \mathrm{ml})$, freezing at $-80^{\circ} \mathrm{C}$, and passage through a French press at $10000 \mathrm{lbf}^{-2}(69 \mathrm{MPa})$. Subsequent steps were as previously described (Tipper et al., 1981; Johnson et al., 1985). The quality of RNA preparations was judged from the patterns of ribosomal and other RNA species seen after agarose gel electrophoresis and staining with ethidium bromide and also by the patterns of translation products (see below). These were highly reproducible.

RNA was further fractionated on sucrose gradients and by acrylamide gel electrophoresis. The use of $40 \%(\mathrm{v} / \mathrm{v})$ dimethyl sulphoxide in the sucrose gradients improved both the resolution and recovery of RNA species. Individual fractions were analysed on agarose gels, and sizes estimated from distance migrated relative to the $23 \mathrm{~S}$ and $17 \mathrm{~S}$ rRNAs and $4 \mathrm{~S}$ tRNAs.

Forespore RNAs were isolated as for total-cell RNA. Selective isolation of mother cell RNA was attempted by lysozyme treatment of $t_{5.5}$ cells in buffer $\mathrm{S}$, as for forespore treatment, followed by suspension of the cells in $\mathrm{m}$ cresol $(5 \mathrm{ml})$ and passage through the French press at $2000 \mathrm{lbf} \mathrm{in}^{-2}(13.8 \mathrm{MPa})$. RNA was recovered from the aqueous phases as above. Light microscopy indicated that $60-80 \%$ of the cells and apparently all of the forespores remained intact during this procedure, but the extent to which the RNA contents of mother cell and forespore compartments were extracted is unknown. RNA recoveries were also variable.

Translation, immunoprecipitation and analysis of products. RNA samples were translated in an Escherichia coli S30 system using L- $\left[{ }^{35} \mathrm{~S}\right]$ methionine as label (Arnaud et al., 1980). The system was optimized, by adjustment of metal ion and RNA concentrations and reaction time, to obtain high-molecular-mass polypeptides from MS2 RNA 
(Miles Research Products) and B. subtilis vegetative cell RNA, as previously described (Arnaud et al., 1980; Johnson et al., 1985). Products were analysed by SDS-PAGE and autoradiography. Patterns seen from translation of total RNA samples isolated from cells at particular stages of sporulation were highly reproducible, and incorporation into specific bands was proportional to total RNA concentration. Where indicated, products from in vitro translation were fractionated by precipitation with antibody to a mixture of $\alpha$ and $\beta$, as described above.

\section{RESULTS}

\section{Purification of $\alpha, \beta, \gamma$ and $\delta$}

$\alpha$ and $\beta$ are the least basic $B$. subtilis ASSPs (pIs 6.58 and 6.67, respectively) and are readily separated from the other ASSPs by fractionation on carboxymethylcellulose columns (Fig. 1, lane 2) (Johnson \& Tipper, 1981). They co-eluted on all ion-exchange columns tested and could not be completely resolved by HPLC on $\mathrm{C}_{18}$ columns even under isocratic conditions. The mixture of $\alpha$ and $\beta$ was fractionated by preparative gel electrophoresis at $\mathrm{pH} 3 \cdot 6$. A final HPLC fractionation removed other contaminants, including small amounts of $\gamma$, which is poorly

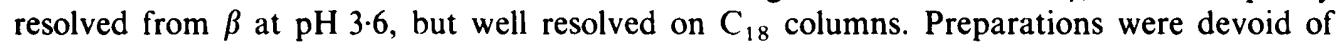
contaminants detectable by HPLC or by electrophoresis at pH 3.6 or in SDS (Fig. 1, lanes 3 and 4).

Because $\delta$ is not extracted from dry-broken spores with $0.52 \mathrm{M}$-acetic acid, $\gamma$, extracted by this procedure, is readily purified by carboxymethylcellulose chromatography (Johnson \& Tipper, 1981 ) or by $\mathrm{C}_{18}$ HPLC (see Methods). The mixture of $\gamma$ and $\delta$ produced by $2 \mathrm{M}-\mathrm{HCl}$ extraction (Fig. 1, lanes 1 and 9) is just as readily fractionated by the same procedures from other ASSPs, but is poorly resolved on either type of column. Complete resolution was achieved by phosphocellulose column chromatography. After fractionation by $\mathrm{C}_{18}$ HPLC to remove residual impurities and salts, each gave a single band on electrophoresis in SDS (Fig. 1, lanes 5 and 6) or at $\mathrm{pH} 4.7$ or 3.6 (not shown).

\section{Amino acid analyses and sequences}

Data previously reported for the approximately $2: 1$ natural mixture of $\alpha$ and $\beta$ demonstrate that both label with $\left[{ }^{35}\right.$ S $]$ methionine and lack Trp, Cys, His and Tyr (Johnson \& Tipper, 1981 ; Johnson et al., 1985). Separate analyses of purified $\alpha$ and $\beta$ confirmed this and also demonstrated the presence of Pro in each, previously thought to be absent (data not shown). Both $\alpha$ and $\beta$ contained over $25 \%$ Glu plus Asp and their amides, consistent with their roles as storage proteins. The data were close to those predicted by the sequences of the $s s p A$ and $s s p B$ genes (Connors et al., 1986a). The sequences determined for $\alpha$ and $\beta$ are aligned and compared with those of the B. megaterium A and C proteins in Fig. 2. Combination of the data from two runs gave unambiguous data for more than 30 residues.

Amino acid contents determined for $\gamma$ and $\delta$ were very similar except for the higher content of Glu plus Gln in $\delta$ (data not shown). Neither contained His, Met, Tyr or Pro. Previous analysis of $\gamma$ indicated the absence of Cys and Trp (Johnson \& Tipper, 1981). Sequence analysis of $\gamma$ and $\delta$ gave identical results for 37 residues, with unambiguous data for at least 33 residues. Analysis of the first 15 residues of a preparation of $\delta$ independently isolated from spores of strain SMY also gave identical results (data not shown). A comparison of the $\gamma$ and $\delta$ sequences with the sequence of B. megaterium ASSP B is shown in Fig. 3.

\section{ASSPS $\alpha$ and $\beta$ and their $m R N A$ s are located in the forespore}

Recovery of ASSPs by acid extraction of dry-broken $t_{5 \cdot 5}$ or $t_{6}$ forespores was $40 \%$ of that from intact spores, and all ASSP species were represented in the same ratios (data not shown). Since the yield of these vigorously cleaned forespores was also $40-50 \%$ of intact sporulating cells, and since $t_{5.5}$ mother cell extracts were essentially devoid of ASSPs detectable by immunoprecipitation, it is concluded that, as in B. megaterium (Setlow, 1981), ASSPs accumulate in the forespores of $B$. subtilis.

Forespores also contained high mRNA activity for $\alpha$ and $\beta$ ASSPs (Fig. 4, lane 4). By densitometry of the $\alpha \beta$ translation product, the actual recovery of $\alpha \beta$ mRNA activity was 55$60 \%$ of that seen in RNA prepared by the same procedure from equivalent quantities of $t_{6}$ whole 


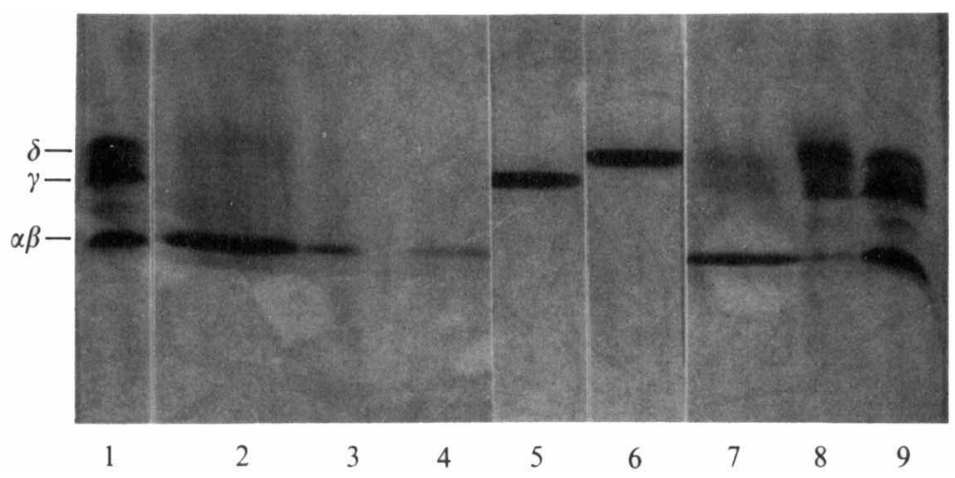

Fig. 1. Gradient (7.5-15\%) SDS-PAGE of ASSP fractions. The mobilities of $\alpha, \beta, \gamma$ and $\delta$ are as indicated. Lanes 1 and 9 , total $2 \mathrm{M}-\mathrm{HCl}$ extracted ASSPs from $B$. subtilis spores. Lane 2, fraction unabsorbed by carboxymethylcellulose (crude $\alpha$ plus $\beta$ ). Lanes 3 and $4, \alpha$ and $\beta$, respectively, after preparative gel electrophoresis at $\mathrm{pH} 3.6$. Lanes 5 and 6 , purified $\gamma$ and $\delta$, respectively, after phosphocellulose chromatography. Lane 7 , fraction eluting late from carboxymethylcellulose: predominantly $\varepsilon$ (comigrating with $\alpha$ and $\beta$; Johnson et al., 1985). Lane 8 , mixture applied to phosphocellulose column.

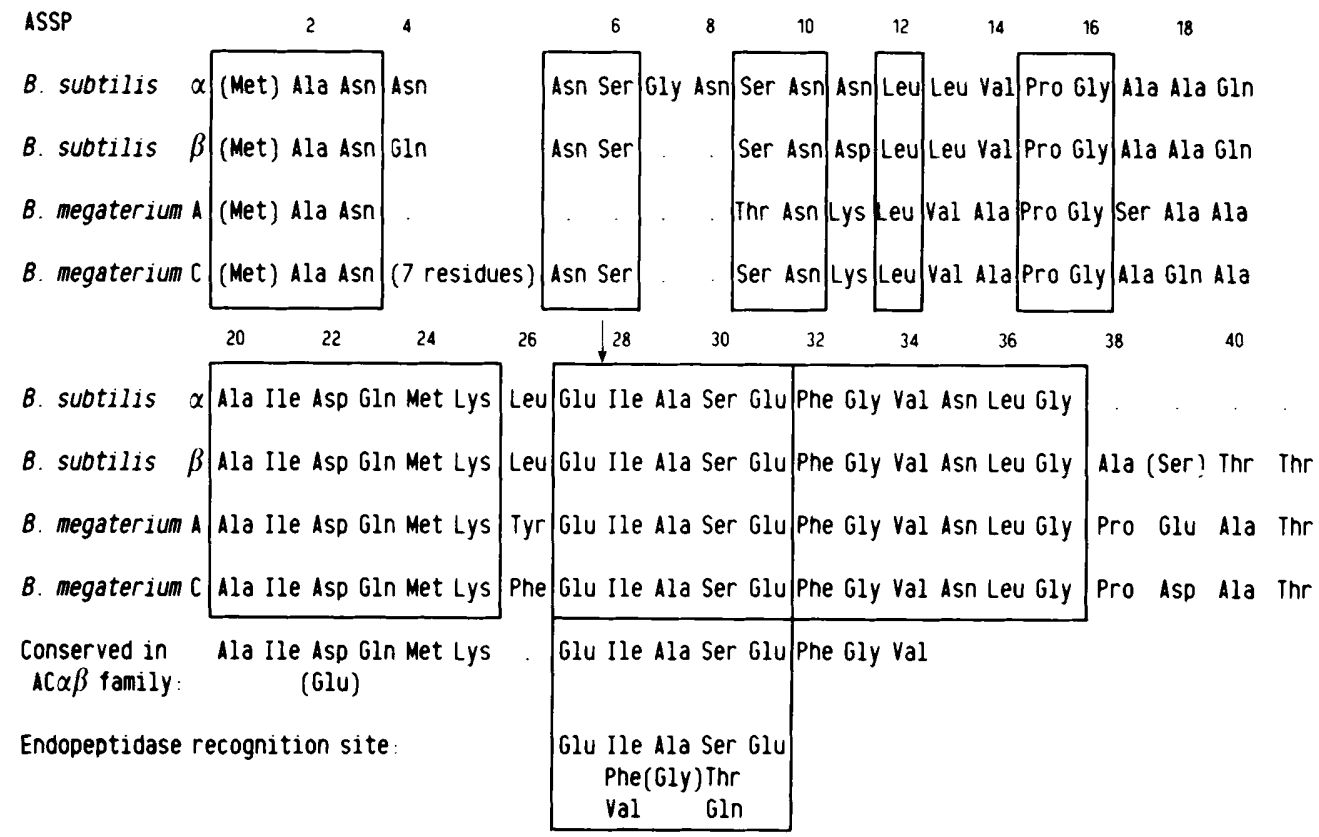

Fig. 2. Homology of $B$. subtilis $\alpha$ and $\beta$ with $B$. megaterium A and C ASSPs. The data for the $B$. megaterium proteins are taken from Fliss et al. (1986). A dot indicates the absence of any corresponding amino acid. Residue numbers indicated are for $\alpha$, assuming removal of $\mathrm{N}$-terminal methionine (Connors et al., 1986a) in vivo. Residue 37 of $\beta$ is probably Asp rather than Ser (see text). The arrow shows the site of cleavage by the ASSP-specific spore endopeptidase. Its consensus pentapeptide recognition sequence (bottom line) is found in all published ASSP sequences. Parentheses indicate a residue found in one example only. The much more extensive sequence conserved in 9 of the 11 members of the $\mathrm{AC} \alpha \beta$ family (see text) is also shown. 

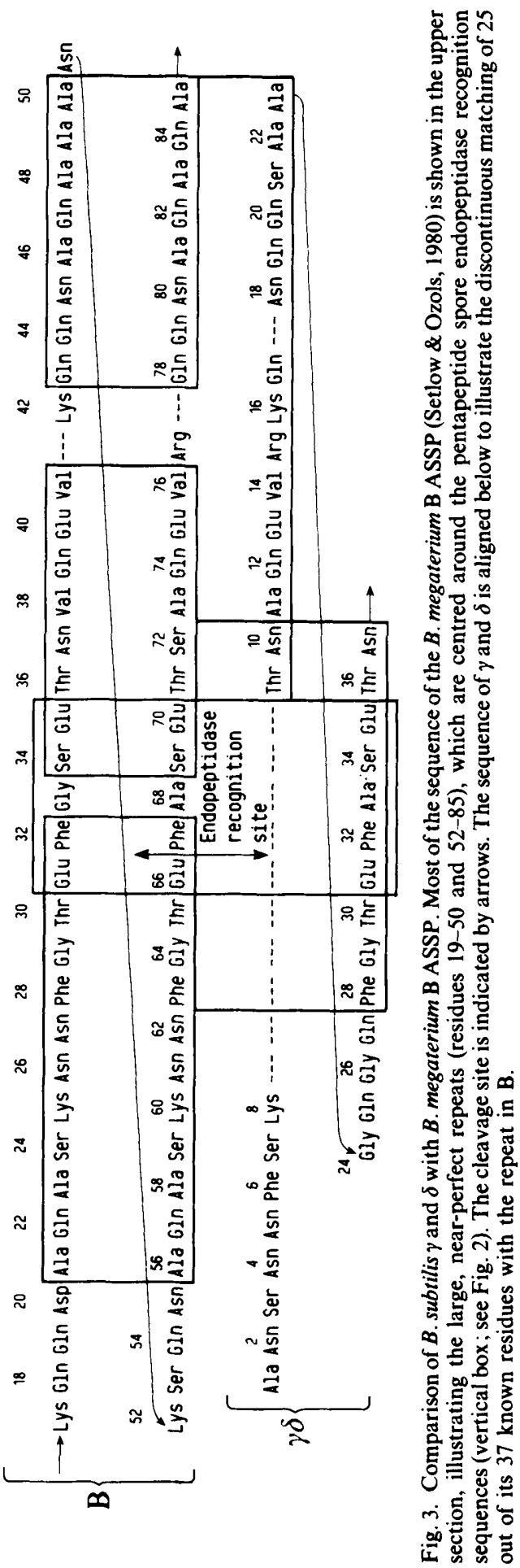


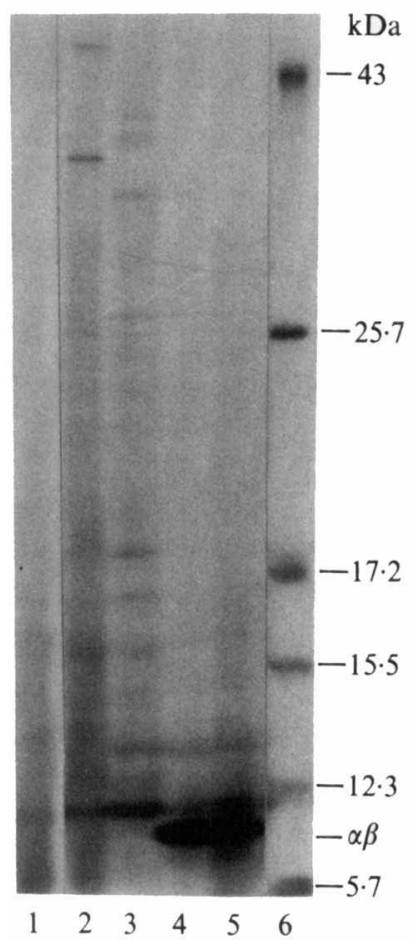

Fig. 4. mRNAs for ASSPs $\alpha$ and $\beta$ are located in forespores. Total products of translation of $B$. subtilis vegetative cell RNA and of various RNA preparations from $t_{6}$ cells, corresponding to equal culture volumes, were fractionated by SDS-PAGE and detected by autoradiography. Lane 1, no RNA added to the $E$. coli S30 preparation. Lane 2, vegetative cell RNA. Lane $3, t_{6}$ mother-cell RNA. The band running above $\alpha \beta$ but below the $12.3 \mathrm{kDa}$ marker is unidentified and comigrates with a band endogenous to the $E$. coli S30 extract (lane 1). Lane $4, t_{6}$ forespore RNA. Lane $5, t_{6}$ whole-cell RNA. Lane 6 shows the positions of Coomassie-stained $\alpha \beta$ and of labelled marker proteins: ovalbumin $(43 \mathrm{kDa}), \alpha$ chymotrypsinogen $(25.7 \mathrm{kDa})$, lactalbumin $(17.2 \mathrm{kDa})$, cytochrome $c(12.3 \mathrm{kDa})$ and thrombin $(5 \cdot 7 \mathrm{kDa})$.

cells (Fig. 4, lane 5). Products from cells or forespores corresponding to identical volumes of culture are shown in each lane of Fig. 4. Immunoprecipitation of these in vitro translation products with anti- $\alpha \beta$ IgG and fractionation at $\mathrm{pH} 3.6$ showed that both whole-cell and forespore RNAs contained messenger for both $\alpha$ and $\beta$ (data not shown).

Mother-cell RNA failed to produce detectable $\alpha \beta$ mRNA activity. Since the low-pressure French press procedure produced RNA giving recognizable patterns of translation products from lysozyme-treated vegetative cells (not shown), and since $\alpha \beta$ mRNA is relatively stable, it seems possible that any $\alpha \beta$ mRNA present in the mother cell should have been detected by this technique. It is concluded that most, if not all, $\alpha \beta$ mRNA is located in the forespore of sporulating cells at $t_{6}$.

$\alpha$ and $\beta \mathrm{mRNAs}$ are $250-350 \mathrm{bp}$ in length

Total RNA from $t_{5.5}$ cells was fractionated on a $10-30 \%$ linear sucrose gradient. RNA was recovered from individual fractions by ethanol precipitation. The translation products from equivalent amounts of RNA are shown in Fig. 5(a) for fractions in the 12S (lane 2) to 4S (lane 9) size range. Products co-migrating with $\alpha$ and $\beta$ were found principally in the 9-6S region, shown in lanes 5-8.

The RNA in the 9-6S region was pooled and refractionated on a second $5-20 \%$ sucrc je gradient. RNA was recovered and analysed by translation, as before (Fig. $5 b$ ). Only the products 

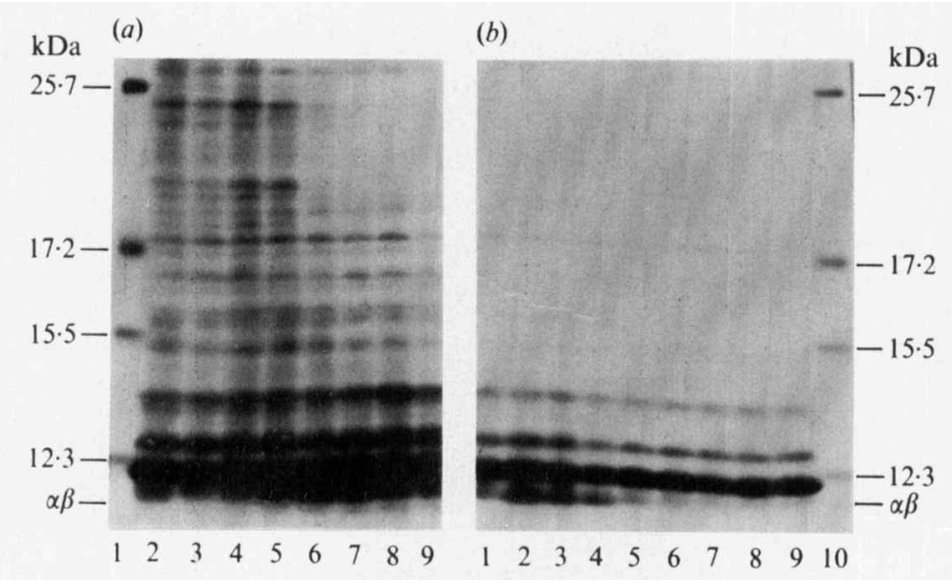

Fig. 5. Sucrose gradient fractionation of mRNAs for $\alpha$ and $\beta$. (a) Total RNA from a 1-litre culture of $B$. subtilis 168 at $t_{5.5}$ was fractionated in a $10-30 \%$ sucrose gradient in $40 \%$ dimethyl sulphoxide. RNA, recovered from individual fractions by ethanol precipitation, was translated and analysed as in Fig. 4. Labelled protein size markers (lane 1) are as in Fig. 4. The position of Coomassie-stained $\alpha \beta$ is also indicated. Lanes 2-9, products from successive gradient fractions in the size range from $12 \mathrm{~S}$ (lane 2 ) to 4S (lane 9). (b) RNA in fractions 5-8 of (a) was pooled and re-fractionated on a 5-20\% sucrose gradient. Lane 10, marker proteins, as in $(a)$; lane 9, endogenous translation products in the $\mathrm{S} 30$ system; lanes 18 , successive fractions from the $8 \mathrm{~S}$ to $5 \mathrm{~S}$ region of the gradient.

of RNA fractions in the 8S (lane 1) to $4 \mathrm{~S}$ (lanes 6-9) region of the gradient are shown: the $\alpha \beta$ mRNA peaked in fractions 2 and 3 , at $7 \mathrm{~S}$.

Total RNA from $t_{6}$ cells was denatured in $50 \%(\mathrm{v} / \mathrm{v})$ formamide, $2 \cdot 2 \mathrm{M}$-formaldehyde $(15 \mathrm{~min}$, $55^{\circ} \mathrm{C}$ ) and fractionated on a $7 \%$ acrylamide gel. Gel bands covering the region from $16 \mathrm{~S}$ to $5 \mathrm{~S}$ were excised and eluted. Translation of the recovered RNAs showed good recovery of $\alpha \beta$ mRNA activity in a narrow band corresponding to 7S RNA, about $300 \mathrm{bp}$ in length (data not shown).

\section{DISCUSSION}

The sequences determined for $\alpha$ and $\beta$ were identical to those predicted by the sequences of the ssp $A$ and sspB genes (Connors et al., 1986a) except that the antepenultimate residue determined for $\beta$ appeared to be Ser while the sequence indicates Asp. Since HPLC signals were becoming marginal at this point and two base changes would be required in this codon to produce Ser, Asp is almost certainly correct. The assignments of $\operatorname{ssp} A$ and $\operatorname{ssp} B$ to $\alpha$ and $\beta$, respectively, are confirmed. Like all ASSPs sequenced, mature $\alpha$, and $\beta$ have lost their $\mathrm{N}$-terminal methionine.

The sequences of $\alpha$ and $\beta$ are aligned and compared with those of the $B$. megaterium $A$ and $C$ proteins in Fig. 2. Numbering follows the $\alpha$ sequence assuming that the $\mathrm{N}$-terminal alanine is residue 2. The best alignment of $\alpha$ and $\beta$ is obtained by the indicated insertion of Gly Asn between residues 6 and 7 of $\beta$. Before this point, a single conservative replacement of Asn by Gln distinguishes $\beta$ from $\alpha$, while the only downstream change is the replacement of Asn in $\alpha$ (residue 11 ) by Asp in $\beta$. Residues 10-35 of $\beta$ are identical to 12-37 of $\alpha$, and the sequences of the $\operatorname{ssp} A$ and $s s p B$ genes (Connors et al., 1986a) indicate that this perfect homology extends for a total of 50 residues with only the $C$-terminal three residues showing a clear difference between $\alpha$ and $\beta$. Derivation of $\alpha$ and $\beta$ from a recent gene duplication event seems probable.

The boxed regions in Fig. 2 show exact homology with the $B$. megaterium proteins. Comparison of the sites cleaved by the specific spore endopeptidase in $\gamma, \mathbf{B}$, and members of the AC $\alpha \beta$ family (Setlow et al., 1980; Yuan et al., 1981) indicates requirement only for a conserved pentapeptide bounded by Glu residues (Fig. 2) within a quite varied context. The presence of this site of specific cleavage (arrow, Fig. 2) clearly indicates conservation of the role of these proteins as polymeric storage forms of amino acids and organic nitrogen to be utilized on 
germination. However, members of the AC $\alpha \beta$ ASSP family share a 24-residue stretch ( $\alpha$ residues 15-37) surrounding the cleavage site, in which only a few conservative changes occur. Marked homology within the $B$. megaterium family has previously been emphasized (Fliss et al., 1986), and persistence of this homology across species lines (Connors et al., 1986a) indicates strong functional constraints on evolution of these sequences. Secondary structure must presumably be conserved in ASSPs to optimize stability in the developing forespore and to allow access of the pentapeptide cleavage site to the specific spore endopeptidase during germination. However, sequence conservation apparently exceeds such requirements. Conservation of domains involved in protein-protein interactions seems possible. For example, cooperative binding to DNA would be consistent with the postulated role for ASSPs in UV resistance (Mason \& Setlow, 1986).

$\gamma$ is always the major ASSP found in acetic acid or $\mathrm{HCl}$ extracts of $B$. subtilis spores, whereas $\delta$ is only seen in significant quantities when stronger acids are used for extraction, and even then its recovery is somewhat variable (Johnson \& Tipper, 1981). Even though $\delta$ migrates more slowly than $\gamma$ on SDS-PAGE, it is possible that it is an artefactual degradation product of $\gamma$, produced during extraction in $\mathrm{HCl}$. It is not a partial deamidation product since it is more basic than $\gamma$ (Johnson et al., 1985). Proteolytic degradation of $\gamma$ to $\delta$, or vice versa, seems unlikely in $2 \mathrm{M}-\mathrm{HCl}$, but cannot be excluded. If neither $\gamma$ nor $\delta$ is an artefact, then either $\gamma$ is derived from $\delta$ by $\mathrm{C}$-terminal processing in vivo, or they derive from independent genes of very recent divergence. The relationship of $\gamma$ to $\delta$ will probably be resolved only by cloning and analysis of the gene or genes involved.

In the $B$. megaterium B protein (Setlow \& Ozols, 1980), residues 21-50 are almost perfectly repeated in residues 56-85 (Fig. 3). The two spore endopeptidase recognition sites (arrow, Fig. 3) fall centrally in these repeats. There is no apparent homology between the flanking peptides and those surrounding the recognition site in the $\mathrm{AC} \alpha \beta$ family. Although $\gamma$ is known to contain two cleavage sites, as in B (Yuan et al., 1981), our sequence only covers the first of these (Fig. 3). This sequence is clearly much more divergent from $B$ than $\alpha$ and $\beta$ are from $A$ and $C$, but distinct homology can be seen for 25 of the 37 known residues. $\gamma$ and $\delta$, besides retaining exactly a decapeptide (residues 28-37) comprising the cleavage site and flanking di- and tripeptides, also retains a 15 -amino-acid sequence which, with variation at two sites, follows this decapeptide in the repeated B sequences. However, this sequence precedes the decapeptide in $\gamma$ and $\delta$ (residues 9-23) (Fig. 3). Whatever the function implied by this sequence conservation, it is apparently compatible with shuffling of these sequence blocks between $\gamma \delta$ and B. It appears that $B$. subtilis and $B$. megaterium have in common at least two families of ASSPs, the first represented by $\alpha, \beta$, $\mathrm{A}$ and $\mathrm{C}$, and the second by $\gamma, \delta$ and $\mathrm{B}$.

Singh et al. (1977) demonstrated that B. megaterium A and B ASSPs accumulate in the forespores of sporulating cells, as we have now shown both for the $\alpha$ and $\beta$ ASSPs of $B$. subtilis and for their mRNAs. Since ASSP synthesis is controlled at the level of transcription in both bacillus species (Dignam \& Setlow, 1980; Tipper et al., 1981; Johnson et al., 1985), the location of ASSP accumulation is determined by exclusive expression of the ASSP genes in this cell compartment. Although this result was anticipated, ASSPs represent a considerable fraction of total forespore protein and the synthetic capacity of forespores is unknown. It was at least plausible that ASSPs could have been synthesized in the mother cell and transported across the two forespore membranes.

The roughly equivalent yields of $\alpha, \beta$ and $\gamma$ originally isolated from spores of $B$. subtilis strain 168 (Johnson \& Tipper, 1981) and the co-expression of ASSP components (Johnson et al., 1985) made it plausible that ASSPs might derive from translation of a polycistronic transcript or that they might be derived post-translationally from a polymeric precursor (Johnson \& Tipper, 1981). The in vitro synthesis of $\alpha, \beta$ and $\gamma$ of mature size (Tipper et al., 1981; Johnson et al., 1985) implies the absence of significant in vitro processing of translation products. The estimated sizes of $\alpha$ and $\beta$ mRNAs (about 300 bases) now indicate that each transcript is monocistronic. This is consistent with the separate map locations identified for the four $B$. subtilis ASSP genes cloned (Connors et al., 1986 b). A common forespore-specific transcriptional control system presumably exists for all coordinately controlled ASSP genes, which include, in $B$. subtilis, at least $\alpha, \beta \gamma$ and $\delta$ (Johnson et al., 1985). The gene products involved remain to be identified. 
This work was supported by grant number Al-10806 to Donald J. Tipper from the National Institute of Arthritis and Infectious Diseases, National Institutes of Health, Department of Health and Human Services. Ms Arnaud and Dr Warburg were supported by grant number AI-18904 to Dr Harlyn O. Halvorson from the same Institute.

\section{REFERENCES}

Arnaud, M., Mahler, I., Halvorson, H. O., BoschWITZ, H. \& KEYNAN, A. (1980). In vitro translation of messenger ribonucleic acid from sporulating and nonsporulating strains of Bacillus subtilis. Journal of Bacteriology 142, 1045-1048.

Connors, M. J., Mason, J. M. \& Setlow, P. (1986a). Cloning and nucleotide sequencing of genes for three small, acid-soluble proteins from Bacillus subtilis spores. Journal of Bacteriology 166, 417-425.

Connors, M. J., Howard, S., Hoch, J. \& Setlow, P. $(1986 b)$. Determination of the chromosomal locations of four Bacillus subtilis genes which code for a family of small, acid-soluble spore proteins. Journal of Bacteriology 166, 412-416.

Curiel-Quesada, E., Setlow, B. \& Setlow, P. (1983). The cloning of the gene for C-protein, a lowmolecular-weight spore-specific protein gene from Bacillus megaterium. Proceedings of the National Academy of Sciences of the United States of America 75, 1428-1432.

Dignam, S. S. \& SETlow, P. (1980). In vivo and in vitro synthesis of the spore-specific proteins $A$ and $C$ of Bacillus megaterium. Journal of Biological Chemistry 255, 8417-8423.

Fliss, E. R., Loshon, C. A. \& Setlow, P. (1986). Genes for Bacillus megaterium small, acid-soluble spore proteins: cloning and nucleotide sequence of three additional genes from this multigene family. Journal of Bacteriology 165, 467-473.

JoHnson, W. C. \& TIPPER, D. J. (1981). Acid-soluble spore proteins of Bacillus subtilis. Journal of Bacteriology 146, 972-982.

Johnson, W. C., Mahler, I., Phillips, K. \& TiPper, D. J. (1985). Transcriptional control of synthesis of acid-soluble spore proteins in sporulating Bacillus subtilis. Journal of Bacteriology 163, 543-551.

LAuriere, M. \& Mosse, J. (1982). Polyacrylamide gelurea electrophoresis of cereal prolamins. Analytical Biochemistry 122, 20-25.

leventhal, J. M. \& Chambliss, G. H. (1982). Synthesis of acid-soluble spore proteins by Bacillus subtilis. Journal of Bacteriology 152, 1117-1125.

Leventhal, J. M., Johnson, W. C., Tipper, D. J. \& Chambliss, G. H. (1981). In vitro synthesis of protein by extracts of Bacillus subtilis. In Sporulation and Germination, pp. 209-213. Edited by H. S. Levinson, A. L. Sonenshein \& D. J. Tipper. Washington, DC: American Society for Microbiology.

Mason, J. M. \& SEtlow, P. (1986). Essential role of small, acid-soluble spore proteins in resistance of Bacillus subtilis spores to UV light. Journal of Bacteriology 167, 174-178.

SerLow, P. (1975). Identification and localization of the major proteins degraded during germination of Bacillus megaterium spores. Journal of Biological Chemistry 150, 8159-8167.

SETLOW, P. (1981). Biochemistry of forespore development and spore germination. In Sporulation and Germination, pp. 13-28. Edited by H. S. Levinson, A. L. Sonenshein \& D. J. Tipper. Washington, DC: American Society for Microbiology.

Setlow, P. \& Ozols, J. (1980). The complete covalent structure of protein $B$. The third major protein degraded during germination of Bacillus megaterium spores. Journal of Biological Chemistry 255, 1044510450.

Setlow, P., Gerard, C. \& Ozols, J. (1980). The amino acid sequence specificity of a protease from spores of Bacillus megaterium. Journal of Biological Chemistry 255, 3624-3628.

Singh, R. P., Setlow, B. \& Setlow, P. (1977). Levels of small molecules and enzymes in the mother cell compartment and the forespore of sporulating Bacillus megaterium. Journal of Bacteriology 130, $1130-1138$.

Tipper, D. J., Johnson, W. C., Chambliss, G. H., Mahler, I., Arnaud, M. \& Halvorson, H. O. (1981). Acid-soluble polypeptides of Bacillus subtilis spores. In Sporulation and Germination pp. 178-181. Edited by H. S. Levinson, A. L. Sonenshein \& D. J. Tipper. Washington, DC: American Society for Microbiology.

Yuan, K., Johnson, W. C., Tipper, D. J. \& Setlow, P. (1981). Comparison of various properties of lowmolecular-weight proteins from dormant spores of several Bacillus species. Journal of Bacteriology 146, 965-971. 